Brit. f. industr. Med., 1966, 23, 37

\title{
Sudden Illness as a Cause of Motor-vehicle Accidents
}

\author{
B. HERNER, B. SMEDBY, and L. YSANDER \\ From the Department of Medicine, Varberg County Hospital, Varberg, and the \\ Department of Social Medicine, University of Uppsala, Sweden
}

Forty-one of the 44,255 road accidents reported to the police in one region of Sweden during 1959-63 were, or probably were, caused by sudden illness in the driver of a motor-vehicle. All 4I were males. The illness was most often due to epilepsy or myocardial infarction. Eight drivers died at the wheel from their disease. No other persons were killed in the $4 \mathrm{I}$ accidents. Only in 19 out of the 4I cases was there any possibility of a previous medical examination having indicated that the man was unfit to drive. In view of this, and the extremely small proportion-about I in I,000- of accidents caused by sudden illness at the wheel, there is little point in providing for general measures such as periodic medical examination to prevent these accidents. Attention should be directed to other types of accidents and other groups of drivers.

One important task for medical research on the prevention of road accidents is to determine how different types of physical and mental impairment affect driving ability. Several organizations, including the British Medical Association (1954), the World Health Organization (1956), and the American Medical Association (1959), have drawn up guides for physicians on how to judge fitness to drive. These guides discuss not only permanent physical handicaps, such as defective vision or hearing and amputated or paralysed limbs, but also disorders which may cause the driver suddenly to lose consciousness or so much self-control that he is likely to cause an accident.

We have collected information on the age and medical requirements for obtaining and keeping a driver's licence for private cars in II countries in Western Europe. ${ }^{1}$ Eighteen is the minimum age in every country except Great Britain, where it is 17 years. No country sets an upper age limit. The Nordic countries and Italy require every applicant to pass a medical examination. In Holland, only persons over 60 need pass a medical examination, and in Switzerland only persons over 65 . The other countries are satisfied with the applicant's word that he is healthy, sometimes combined with a rough

\footnotetext{
Received for publication May 12, 1965.

'Belgium, Denmark, Finland, France, Great Britain, Italy, Netherlands, Norway, Sweden, Switzerland and West Germany (at the time, in Belgium a licence for driving a private automobile was not required, but the driver had to be at least 18 years old).
}

check on his vision and hearing undertaken by an examiner who is not medically qualified. Persons who obtain driving licences in Sweden, Switzerland, and Western Germany keep them for the rest of their lives. In the other countries, licences are valid for three to five years only, and in most of these the same medical requirements must be met at each renewal. Most of these countries also arrange for licences of shorter duration when the driver has a disease or defect which might be dangerous to traffic.

In Sweden, applicants for a driving licence must submit a special form of medical certificate. Any physician may complete this certificate. The physician is required to ask the applicant whether he has ever had epilepsy, fainting spells or other disorders of consciousness, dizziness, heart disorder, diabetes, renal disorders, mental disease, or any form of severe bodily injury. $\mathrm{He}$ is required to note in the certificate whether the applicant shows any signs of organic heart disease or disease of the nervous system or clear evidence of mental defect. $\mathrm{He}$ is also required to test the visual acuity and visual field of the applicant, test his hearing, examine his urine for sugar and albumin, make a physical examination of his heart and, if indicated, measure his blood pressure and make a cursory test of his reflexes.

Swedish physicians are not compelled to report the case if a driver has a disease which might make him dangerous in traffic. However, the National Board of Health recommends physicians to report 
whenever they discover one of a specified list of diseases in a person who possesses a driving licence. They are asked to send these reports to the Senior Medical Officer of Health in their county, and this officer is required to arrange for an investigation to establish whether the driver in question should be deprived of his licence temporarily or permanently. A report of this kind from a physician is not considered to be an offence against the law of privileged communication. Nevertheless, it seems that only a few physicians report cases of this kind. In most cases, probably, the physician exacts a promise from his patient to stop driving, and the matter never comes before the authorities.

Some persons are granted driving licences even when they have epilepsy, diabetes, or one of the other diseases considered to constitute a driving hazard. These persons are required to remain under regular medical supervision and to submit medical certificates at specified intervals.

\section{Official Statistics and Literature}

From time to time a case in which disease in a driver has caused a serious accident receives publicity, and demands are made that something be done to prevent further incidents of the kind. In Sweden, it is commonly demanded that all drivers should undergo medical examination at regular intervals. But exactly how often acute illness at the wheel leads to road accidents is something about which we have very little information. The need for research on this is often expressed and also the need for research to show what illnesses in a driver constitute a danger to traffic. New legislative measures should be based on the results of research of this kind, not on theories about what is likely to be a danger to traffic.

Some information about the rôle of disease in road accidents can be obtained from the official statistics of different countries. Several countries maintain records of the opinion of the police about factors contributing to accidents. Thus, in Great Britain, disease in motorists was considered to contribute two per $\mathrm{I}, 000$ of all road accidents involving personal injury reported in 1958 (Ministry of Transport, 1959). In the United States, illness in the driver was considered to cause two per 1,000 of the motor vehicle accidents in 1959 (Accident Facts, 1960). Physical defect or disease in the motorist was reported in three per 1,000 of the traffic accidents in West Germany in 1953-57 (Bohnenkamp, 1960). In Norway in 1954-57 (Samferdselstatistikk, 1959) physical disease in the driver was reported in one per 1,000 of the accidents. In Denmark in 1953-59 (Faerdselsuheld, 1953-59) two per 1,000 of all the accidents causing personal injury were attributed to sudden illness at the wheel. In Sweden, two per 1,000 of the road accidents in 1956-60 were considered to have been wholly or partly due to disease, pain, unpleasant sensations, or similar conditions in drivers (Vägtrafikolyckor, 1956-60).

Thus, although the statistics are collected in different ways in different countries, they agree on the whole that disease plays only a minor part in road accidents. But too much reliance should not be placed on these statistics. It is often difficult to assess the part played by physical disease in an accident, and the official statistics are mostly based on the opinion of a layman. Many of the diseases or defects noted by the police or reported by the driver may not have had anything to do with the accidents in question. On the other hand, some cases in which chronic or acute disease was partially causative of the accident probably never get into the statistics. The most valuable information on this point comes from investigations carried out by physicians.

An example of a medical investigation of this kind is Norman's study (1958, 1960) of the bus drivers in London Transport. During the II years from 1949 to 1959 , among about 20,000 drivers, 46 drivers lost consciousness suddenly while driving; in 14 cases it was because of myocardial infarction, in eight probably because of epilepsy, and in five because of simple fainting. An accident occurred in 26 of these cases, but in only a few cases was anyone else injured. In view of the approximately 220,000 driveryears which this study covered, it is apparently rare that a driver becomes unconscious at the wheel. The men in this study, however, were a selected and medically supervised group of professional drivers.

The opinion has been expressed that undiagnosed or improperly managed epilepsy and diabetes are more dangerous than heart disease and cause most instances of loss of consciousness at the wheel (McFarland and Moore, I957). According to Norgaard (I96I), 400 traffic accidents, which might have been due to disease in the driver, were reported to the National Board of Health in Denmark over a period of five years. Most were cases of epilepsy, hypoglycaemia in diabetics, and simple fainting. The research of Gerritzen (1959), Pannhorst (1959), and Copplestone (1959) on the driving danger associated with diabetes, however, and of Holzbach (1957) on epilepsy indicates that diabetes and epilepsy are of little danger to traffic.

Dotzauer and Naeve, studying a German series covering 20 years, found that only 14 persons died while driving out of approximately 4,000 who died suddenly from coronary disease (Bohnenkamp, 1960). Schwarz (1960) reported that over a period 
of 25 years in Zürich only I4 persons died of heart disease while they were driving, and that no one else was injured as a consequence. Hoffmann (1963) reported that during ro years in Bonn, 31 persons experienced a myocardial infarct while driving and this led to a traffic accident in ro cases.

Most of these data were obtained from studies made for different purposes and do not give clear or reliable information on the frequency of sudden illness at the wheel.

\section{The Present Investigation}

In order to investigate the number and type of accidents caused by sudden illness in drivers of motor-vehicles, one of us (Herner, 1959) planned an investigation, a report of which follows. We collected and analysed accidents of this type which occurred in the five-year period 1959-63 in two counties in Western Sweden $(800,000$ inhabitants), one including the city of Göteborg. We studied only accidents which resulted in investigation by the police in order to exclude minor accidents and to have a specific background population. Every year the police in this region sent us the reports of all accidents which could be suspected to be at least partly due to sudden illness. We also studied the police reports on all accidents in the same region in which a driver died to see whether there were any in which the police had not realized that sudden illness could have been the main or a contributory cause of the accident. In addition, we asked all the hospitals in the region if they knew of any cases of sudden illness at the wheel. In every case discovered we studied all the documents available at the police offices and obtained information from the physicians and hospitals concerned. The investigation was restricted to a limited region in order to facilitate personal contact with those who supplied information.

\section{Results}

We came to the conclusion that $4 \mathrm{I}$ out of the 44,255 traffic accidents reported to the police in the region studied were, or probably were, caused by sudden illness in the driver of the vehicle. This gives a rate of about one per 1,000 . Thirty-one drivers were driving a private automobile, six were lorry-drivers, one was a taxi-driver, and three were motor-cyclists. The police notified us of nearly all the cases. A few were first reported by the hospitals, and two we obtained by studying the cases of II8 drivers who died in traffic accidents during the period in question.

Table I shows the $4 \mathrm{I}$ cases according to the cause of illness and the age of the driver. All 4I were men. Epilepsy was the most common cause, occurring in I2 men, two of whom were found to have brain tumours. The next most common cause was myocardial infarction. The diagnosis was not clear in the groups designated 'Sudden loss of self-control without actual loss of consciousness' and 'Brief loss of consciousness of obscure origin'. Most of the 4I men were aged between 40 and 59 years. Six out of Io of those under 40 had epilepsy. Eight drivers died at the wheel from their disease.

Table II shows the number of accidents causing injury and damage. Six of the drivers were severely injured, but none of them to a fatal degree, as far as could be judged. All seven drivers with a myo-

TABLE I

Motor-vehicle Accidents Caused by Sudden Illness at the Wheel, According to Cause of Illness AND AGE OF DRIVER

\begin{tabular}{|c|c|c|c|c|c|c|c|}
\hline \multirow[t]{2}{*}{ Cause of Illness } & \multicolumn{6}{|c|}{ Age of Driver (yrs.) } & \multirow[t]{2}{*}{ Total } \\
\hline & $18-29$ & $30-39$ & $40-49$ & $50-59$ & $60-69$ & $70-79$ & \\
\hline Epilepsy & 2 & 3 & 3 & 2 & & & I0 \\
\hline Cerebral tumour with epileptic fit & $\mathbf{I}$ & & I & & & & 2 \\
\hline Subarachnoid haemorrhage & $\mathbf{I}$ & & & $\mathbf{I}$ & & & 2 \\
\hline Cerebral haemorrhage & & & & $\mathbf{I}$ & & & $\mathbf{I}$ \\
\hline Myocardial infarction & & & 3 & $\mathbf{I}$ & 2 & $\mathbf{I}$ & 7 \\
\hline Arteriosclerotic or rheumatic heart disease with Adams- & & & & & & & \\
\hline Stokes syndrome & I & & & I & & I & 3 \\
\hline Diabetes with hypoglycaemia & & & $\mathbf{I}$ & $\mathbf{I}$ & $\mathbf{I}$ & & 3 \\
\hline Psychosis with acute confusional state & & & $\mathbf{I}$ & & & & $\mathbf{I}$ \\
\hline $\begin{array}{l}\text { Sudden loss of self-control without actual loss of } \\
\text { consciousness, e.g., acute nausea, coughing attack } \\
\text { Brief loss of consciousness of obscure origin, e.g., simple }\end{array}$ & $\mathbf{r}$ & & 4 & 2 & & & 7 \\
\hline fainting & & $\mathbf{I}$ & 2 & 2 & & & 5 \\
\hline Total & 6 & 4 & 15 & II & 3 & 2 & 4I \\
\hline
\end{tabular}


TABLE II

Motor-vehicle Accidents Caused by Sudden Illness at the Wheel, According to Cause of Illness and Resultant d Damage to Person and Property

Cause of Illness

\begin{tabular}{|c|c|c|c|}
\hline \multirow{2}{*}{$\begin{array}{l}\text { No. of } \\
\text { Accidents }\end{array}$} & \multicolumn{3}{|c|}{ No. of Accidents Causing } \\
\hline & $\begin{array}{l}\text { Driver } \\
\text { Injury }\end{array}$ & $\begin{array}{l}\text { Other Person } \\
\text { Injury }\end{array}$ & $\begin{array}{l}\text { Property } \\
\text { Damage }\end{array}$ \\
\hline Io & 3 & 2 & 6 \\
\hline 2 & 2 & 2 & 2 \\
\hline 2 & I & & 2 \\
\hline I & & & I \\
\hline 7 & 2 & & 4 \\
\hline 3 & 2 & & 3 \\
\hline 3 & I & & 3 \\
\hline I & & & I \\
\hline 7 & I & $\mathbf{I}$ & 6 \\
\hline 5 & 2 & 2 & 3 \\
\hline 41 & 14 & 7 & 31 \\
\hline
\end{tabular}

cardial infarct died at the wheel, but no one else was injured as a result, and in only four cases did any damage to property ensue. These seven apparently had time to take precautions with their car before they died. Sixteen drivers had their licences revoked after the accident. Some of the other drivers agreed to stop driving on the advice of their physicians.

As pointed out in the Lancet (1957), it is difficult if not impossible to detect all the physical disorders that may lead to an accident in the future. As far as we could judge, in only 19 of our 41 cases could previous medical examination have indicated that the driver was potentially dangerous. Relatively few of the $4 \mathrm{I}$ accidents could have been prevented in this way. Table III shows in which cases, in our opinion, it might have been possible to prevent the accident.

\section{Conclusions}

It appears from this investigation that the most frequent causes of sudden illness at the wheel are epilepsy and cardiovascular disease. But sudden illness is a rare cause of traffic accidents-only one out of every thousand in the present investigation. The possibility of preventing this rare type of accident seems so limited that there appears to be no point, in our country at least, in introducing any new general measures of prevention. In other words, we are against having all drivers undergo periodical medical examinations, perhaps with the exception of a simple check on sight and hearing. The amount of extra work that a more thorough examination would entail would be out of proportion to the extent to which it might benefit road safety.

TABLE III

Motor-vehicle Accidents Caused by Sudden Illness at the Wheel, According to Cause of Illness and Possibility of Prevention

Cause of Illness

$\begin{array}{lll}\text { No. of } & \text { Prevention } & \begin{array}{l}\text { Prevention } \\ \text { Apparently } \\ \text { Accidents }\end{array} \\ & \text { Possible } & \begin{array}{l}\text { Impossible } \\ \end{array}\end{array}$

Epilepsy

Cerebral tumour with epileptic fit

Subarachnoid haemorrhage

Cerebral haemorrhage

Myocardial infarction

Arteriosclerotic or rheumatic heart disease with Adams-Stokes syndrome

Diabetes with hypoglycaemia

Psychosis with acute confusional state

Sudden loss of self-control without actual loss of consciousness, e.g., acute nausea, coughing attack

Brief loss of consciousness of obscure origin, e.g., simple fainting

Total

$\begin{array}{rrr}\text { I0 } & 6 & 4 \\ 2 & \text { I } & \text { I } \\ 2 & & 2 \\ 1 & & 1 \\ 7 & 7 & \\ 3 & 3 & 3 \\ 3 & & \\ 1 & \text { I } & 6 \\ 7 & \text { I } & 5 \\ 5 & & 22\end{array}$


It will never be possible to prevent the occasional severe and dramatic accident due to sudden illness at the wheel. But accidents of this kind are obviously rare. This does not mean that physicians can shed their responsibility for patients who constitute a potential traffic risk. The best way for these diseases to be discovered in their early stages is for the patients to have complete trust in their doctors.

Legislation requiring physicians to report cases of disease entailing a possible traffic risk would deter people with these diseases from going to a physician, for fear of losing their licences. Such patients would not receive the treatment they need, and compulsory reporting would thus defeat the purpose for which it was intended and lower traffic safety instead.

Other causes of traffic accidents need more research than does sudden illness at the wheel. For example, official statistics show that young drivers are responsible for a disproportionate number of traffic accidents. This was borne out by the present investigation : $40 \%$ of the drivers in the 118 accidents in which the driver was killed were under 25 years.

It is apparently in the interests of road safety for drivers with chronic disease to undergo regular medical examination in order to retain their licences (Herner and Ysander, 1962; Ysander, 1965; 1966). It might be useful also to restrict the driving privileges, for example by issue of temporary licences, of people of other categories known from epidemiological studies to be a particular hazard in traffic.
REFERENCES

Accident Facts (1960). National Safety Council, Chicago.

American Medical Association (1959). Medical Guide for Physicians in Determining Fitness to Drive a Motor Vehicle. F. Amer. med. Ass., 169, 1195.

Bohnenkamp, H. (1960). Hefte z. Unfallheilk., No. 62, p. 20.

British Medical Association (1954). Memorandum on Medical Standards for Road, Rail and Air Transport, cited by Norman, L. G.

Copplestone, J. F. (1959). Brit. F. industr. Med., 16, 170.

Faerdselsuheld (Road Traffic Accidents) (1953-59). Copenhagen, 1955-60.

Gerritzen, F. (1959). In Diabetes Mellitus. Proc. Third Congr. int. Diabetes Federation, Düsseldorf 1958; p. 689. Thieme, Stuttgart.

Herner, B. (1959). Svenska Läk.-Tidn., 56, 34. and Ysander, L. (1962). Ibid., 59, 125 .

Hoffmann, H. (1963). Münch. med. Wschr., 105, 1785.

Holzbach, R. (1957). Zbl. Verkehrs-Med., 3, 123.

Leading article (1957). Lancet, 2, 627.

McFarland, R. A., and Moore, R. C. (1957). New Engl. F. Med., 256, 792, 837, and 890 .

Ministry of Transport (1959). Road Accidents 1958. H.M.S.O., London.

Norgaard, A. (196r). Ugeskr. Lag., 123, 947.

Norman, L. G. (1958). Lancet, 2, 807.

(1960). Ibid., I, 1039.

Pannhorst, R. (1959). In Diabetes Mellitus. Proc. Third Congr. int. Diabetes Federation, Düsseldorf 1958; p. 691. Thieme, Stuttgart.

Samferdselstatistikk (Transport and Communication Statistics) (1959). Vols. I-2. Oslo.

Schwarz, F. (1960). Med. Klin., 55, 870.

Vägtrafikolyckor (Road Traffic Accidents) (1956-60). Stockholm, 1958-62.

World Health Organization (1956). Guiding Principles in the Medical Examination of Applicants for Motor Vehicle Driving Permits. Geneva (mimeograph WHO/Accid. Prev./I Rev. 2).

Ysander, L. (1965). Läkartidningen, 62, 263.

- (1966). Brit. F. industr. Med., 23, 28. 